Sc Danko Jovanović,
pukovnik, dipl. inž. VP 5055, Beograd

\section{RAD UPRAVNIH ORGANA LOGISTIČKE PODRŠKE U PRIPREMI OPERACIJE*}

UDC: $355.133 .4: 355.41: 355.42 / .43$

Rezime:

U radu su navedeni osnovni zadaci komande operativnog nivoa, kao i organa logističke podrške u pripremi operacije. Istaknut je značaj procene situacije, poznavanje snaga neprijatelja, mogući uticaj dejstva neprijatelja na sopstvene snage, snage za logističku podršku i infrastrukturu. Prikazan je praktičan podsetnik za rad, sa proračunom vremena za podnošenje predloga, pri sektorskom metodu rada komande korpusa.

Ključne reči: operacija, procena situacije, odluka, zapovest, plan, gotovost.

\title{
FUNCTIONING OF LOGISTIC SUPPORT MANAGEMENT BODIES IN OPERATION PLANNING
}

Summary:

The study presents basic tasks of a command at the operating level and logistic support bodies in operation planning. It stresses out the importance of estimating a situation, gathering information on enemy forces and possible effects on one's own forces, supply support and infrastructure. It also contains a useful memo with a help in calculating time needed for submitting proposals and intended for planning sector work at the corps command level.

Key words: operation, estimation of a situation, decision, order, plan, readiness.

\section{Uvod}

Uspešnost rada vojnih komandi zavisi, u velikoj meri, i od uspostavljene organizacije rada na komandnom mestu. Komandno mesto može biti na svakodnevnoj lokaciji (mirnodopskoj) ili na posebno uređenom prostoru za rad. Prema nameni komandno mesto može biti [10]:

- osnovno (OKM) - sastoji se od komandne grupe, pomoćne grupe i centra veze, a organizuju ga komande svih nivoa. Na njemu se obavljaju aktivnosti rukovođenja i komandovanja potčinjenim jedinicama $\mathrm{u}$ toku priprema $\mathrm{i}$ izvođenja

* Rad je saopšten na simpozijumu „Teorijski i praktični aspekti savremenih operacija“ 20. aprila 2004. u Beogradu. borbenih dejstava. OKM se razmešta na težištu borbenih dejstava, na prostoru koji obezbeđuje potrebne uslove za rad i adekvatnu zaštitu ljudstva i sredstava;

- logističko (LoKM) - sastoji se od operativno-logističke grupe, opšte grupe, pomoćne grupe i centra veze, a organizuju ga komande združenih taktičkih jedinica $i$ viši sastavi. Na LoKM se razmešta deo komande koji je namenjen za realizaciju logističke podrške, a ono može da preuzme ulogu osnovnog komandnog mesta u određenim uslovima, zbog čega se ojačava odgovarajućim kadrovima. Načelno razmešta se u rejonu rasporeda logističkih jedinica;

- rezervno (RKM) - uređuju i po potrebi posedaju jedinice višeg ranga, 
kada za to postoji potreba. Ono mora da obezbedi sve neophodne uslove kao i OKM;

- istureno (IKM) - organizuje se u uslovima kada je otežano komandovanje sa OKM, i kada je potrebno da se ispolji jači uticaj na tok borbenih dejstava. IKM može biti i na KM (osmatračnici) potčinjene jedinice ili u njegovoj blizini;

- objedinjeno (ObKM) - uređuje se i formira kada je potrebno organizovati rad različitih komandi ili njihovih predstavnika na jednom mestu (KoV, RV, RM, MUP,...);

- lažno (LKM) - organizuje se u sklopu operativnog maskiranja.

Za sve vrste komandnih mesta predviđa se i planira naredni rejon razmeštaja.

Osnovni uslov za uspešnu realizaciju zadataka je dobro osmišljena i postavljena organizacija rada komandi i njenih sastava. Zbog toga je potrebno stalno preduzimati neophodne mere za iznalaženje najboljeg oblika rada svake celine. Svaki deo komande mora usmeriti svu svoju energiju na realizaciju osnovnog zadatka koji je nametnut komandi kao celini. Osnovni elementi organizacije rada svake komande su ciljevi i zadaci postavljeni pred ljudstvo koje sačinjava komandu, sredstva, prostor i vreme za koje treba realizovati postavljene zadatke.

Ciljevi su definisane vrednosti koje treba sačuvati ili postići, i u tom smislu mogu biti opšti i posebni. Zadaci su planirane i normativno regulisane aktivnosti kojima se ostvaruju postavljeni ciljevi. Za savremen i efikasan rad komande presudnu ulogu ima kvalifikaciona struktura kadrova i uspostavljena organizacija rada. Kvalifikaciona struktura komande određena je formacijom, ali od umešnosti pojedinaca na rukovodećim mestima zavisi stepen realizacije postavljenih zadataka.

Svaka komanda mora da ima razrađena osnovna organizaciona dokumenta, a posebno:

- pregled prioritetnih zadataka;

- razrađenu šemu organizacione strukture, sa prikazanim odnosima između svih elemenata komande;

- pravilnik o opštim i posebnim dužnostima komande, usklađen sa važećim pravilima i propisima;

- šemu razmeštaja organa komande;

- podsetnik za rad komande posle prijema zadatka, sa razrađenim postupcima za sve organe komande;

- pregled normi za realizaciju pojedinih zadataka i izradu dokumenata;

- pregled stanja ljudstva i sredstava.

Pored navedenih dokumenata svako lice na svojoj formacijskoj dužnosti treba da koristi i određen broj akata koje obrađuje i ažurira u svakodnevnom radu. Prikupljanje i obrada podataka u velikoj meri zavisi od razvijenosti $\mathrm{i}$ funkcionisanja informacionih tokova $u$ svakoj komandi. Nadležni rukovodilac na određenom nivou komande određuje metod rada i grupisanje delova komande, radi ostvarenja sledećih osnovnih funkcija:

- upravljanja, kao funkcije kojom se određuju ciljevi, odlučuje o svim pitanjima i postavljenim zadacima u skladu sa propisanom regulativom; 
- rukovođenja, kao delatnosti kojom se usmeravaju pojedinci, organizacijske celine i vojna organizacija u celini, u realizaciji ciljeva i zadataka. Rukovođenje ostvaruju pojedinci i organizacijske celine na određenom nivou, sa osnovnim karakteristikama društvenog odnosa (odnos pretpostavljenipotčinjeni) i procesa rada čoveka ili komande, pri čemu se ispoljavaju tri vrste odnosa:

- komandni odnos, koji predstavlja suštinu odnosa u vojsci čime se postiže neophodna hijerarhijska struktura. Svako narušavanje linije komandovanja predstavlja neorganizovanost koja može izazvati posledice;

- funkcionalni odnos, koji se uspostavlja radi skladnog izvršavanja zadataka;
- štabni odnos, koji predstavlja ustaljeni način rada i odnosa između donosioca odluke i ostalih organa komande koji obavljaju odgovarajuće analize (procene), predlažu način realizacije i prate izvršenje zadatka;

- izvršavanja, kao procesa kojim se materijalizuju postavljeni ciljevi i zadaci. U sistemu rukovođenja i komandovanja funkciju izvršavanja ostvaruju svi pripadnici vojne organizacije.

Rukovođenje i komandovanje realizuje se na tri nivoa: strategijskom, operativnom i taktičkom. Kao proces rada zasniva se na načelima: jedinstva, sigurnosti, neprekidnosti, elastičnosti, efikasnosti, operativnosti i principima štabnog rada $i$

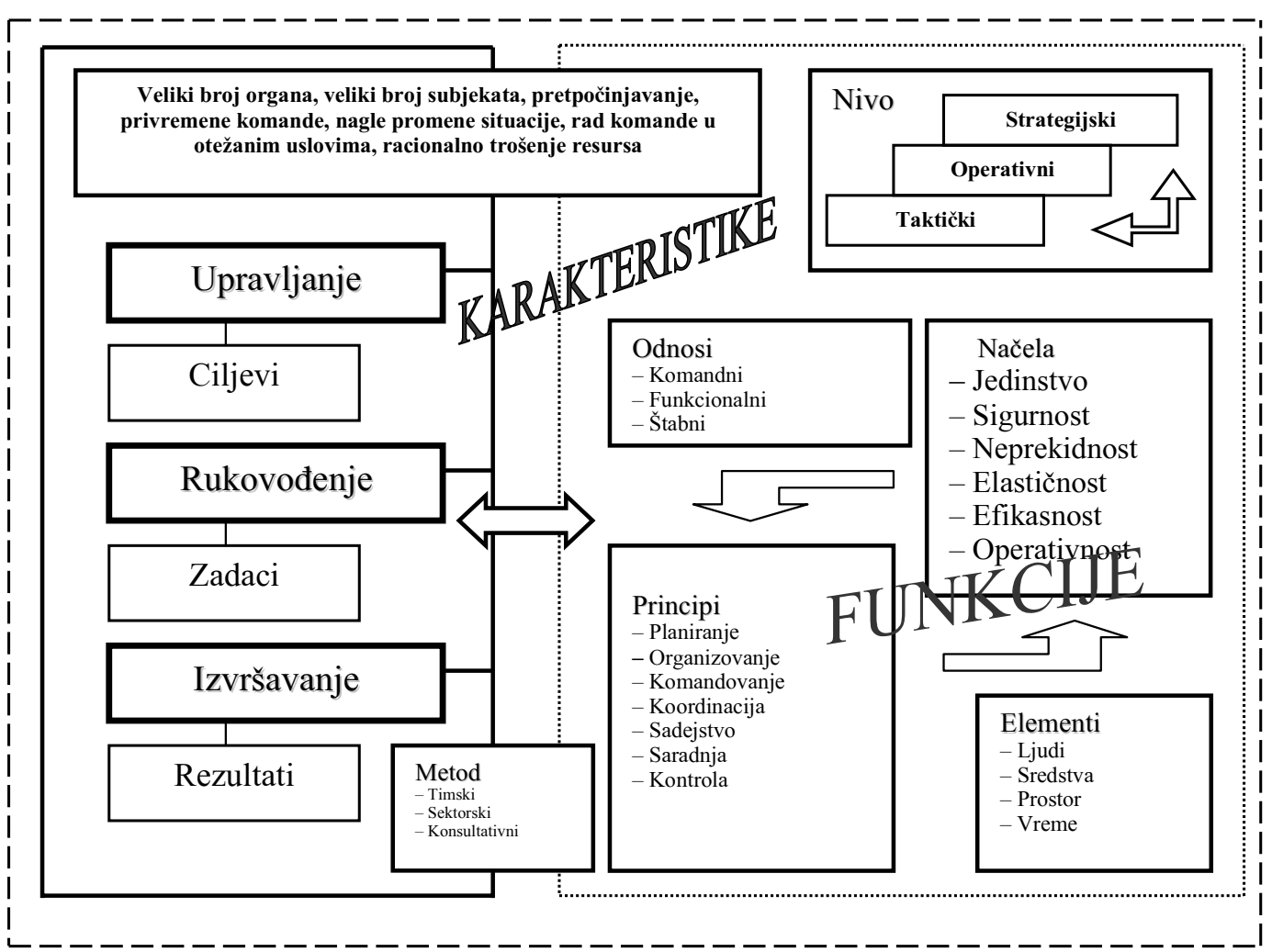

Sl. 1 - Karakteristike rukovođenja i komandovanja 
međusobno povezanim funkcijama kojima se izvršava zadatak, a to su: planiranje, organizovanje, komandovanje, koordinacija, sadejstvo, saradnja i kontrola.

Podela rada u komandama obavlja se u skladu sa opštim načelima organizacije štabnog rada. Procesi rada i nametnuta situacija osnova su za grupisanje i razmeštaj organa komande. Štabni metod rada je okvirni metod i osnova za primenu drugih posebnih metoda, koji mogu biti:

- timski - način rešavanja složenih problema radom više lica organizovanih u timsku grupu;

- sektorski - oblik štabnog rada pri čemu se proces rada na donošenju i realizaciji odluke odvija odvojeno u organima (organizacijskim celinama - sektorima), (predlozi se podnose u vidu referata);

- konsultativni - sprovodi se kada su učesnici ranije upoznati sa zadatkom, pa na zahtev nadležnog lica iznose svoje mišljenje o načinu realizacije postavljenog zadatka.

\section{Sažeti prikaz rada organa logističke podrške}

Svaka komanda teži efikasnom radu. Komande na operativnom nivou, zbog svoje specifičnosti, moraju da regulišu radnje pisanim aktima, a $\mathrm{u}$ isto vreme da budu efikasne i racionalne u utrošku vremena, kako bi preostalo što više vremena jedinicama za adekvatnu pripremu za izvođenje borbenih dejstava. Umešnost za uspostavljanje pravilne organizacije rada u velikoj meri doprinosi da organi komande brzo i pravilno shvate situaciju i aktivno učestvuju u donošenju odluke.
Logistička podrška (LoP) u savremenim borbenim dejstvima dobija sve veći značaj, zbog velike uloge tehničkog faktora i sve izraženije potrebe za efektnim obezbeđenjem, uz što manje troškove. Organi logističke podrške uvek moraju raspolagati adekvatnim pokazateljima koji treba da budu dostupni svim licima koja učestvuju u procesu donošenja odluka. Na slici 1 prikazane su karakteristike i funkcije vojnog sistema. Ističe se princip komandovanja, kao alat za ostvarenje ciljeva realizacijom postavljenih zadataka koji se ostvaruju elementima sistema, a koji su adekvatno, na više nivoa, uspostavili odnose poštujući predviđena načela sistema rukovođenja i komandovanja.

Na slici 2 prikazan je rad komande u fazi pripreme, donošenja i realizacije odluke. Navedeni prikaz je načelan i predstavlja pokušaj da se na skraćen način i sažeto prikaže na jednom mestu rad komande operativnog nivoa.

Na slikama 4 i 4 a prikazan je rad organa logističke podrške u pripremi predloga koje pomoćnik komandanta za logistiku treba da izloži komandantu usmeno ili da podnese pisani referat, u zavisnosti od uspostavljene metodologije rada komande. Od pravilnog rada organa logističke podrške u velikoj meri zavisi pravilno angažovanje izvršnih organa LoP, kao i adekvatna i blagovremena popuna $\mathrm{i}$ utrošak materijalnih rezervi koje jedinicama stoje na raspolaganju.

Nakon podnetih predloga i donošenja odluke sledi njena realizacija prenošenjem zadataka na potčinjene i sačinjavanjem adekvatnih planova koje treba realizovati. 


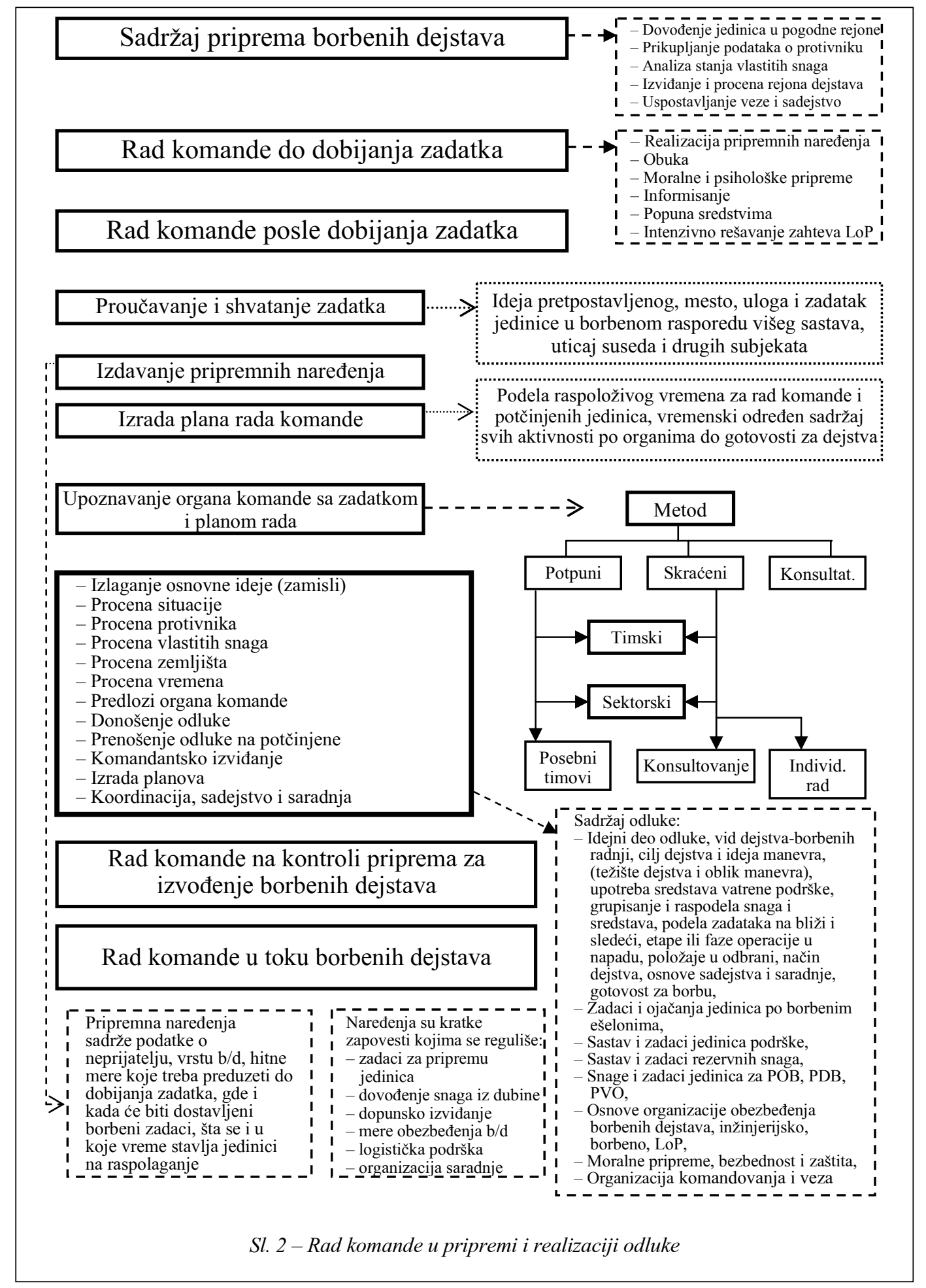


U zavisnosti od metoda rada komande, organi LoP se upoznaju sa zadatkom u sklopu upoznavanja ostalih članova komande ili posebno u okviru organa. NOL je učestvovao u proučavanju i shvatanju zadatka i izdavanju pripremnih naređenja. Osnovna ideja - zamisao komandanta sadrži:

Vid dejstva, cilj dejstva, oblik manevra, težište dejstava, grupisanje snaga, podela zadataka, gotovost.

- Prenošenje osnovne ideje (zamisli)

- Planiranje rada organa LoP

- Procena situacije

1. Procena protivnika

2. Procena vlastitih snaga

3. Procena zemljišta

4. Procena vremena

- Predlozi organa logistike

- Formulisanje i izlaganje predloga PKLo komandantu (referat)

- Prenošenje odluke na potčinjene

- Izviđanje organa za logistiku

- Izrada planova logističke podrške

- Koordinacija i saradnja

1. Procena protivničkih snaga

- jačina

- sastav i raspored

- dejstva iz vazdušnog prostora

- grupisanje po pravcima

- mogući manevar i način dejstva

- mogući desant $i$ angažovanje spec. snaga

- upotreba NHB oružja

- mogući uticaj snaga protivnika na sadržaje LoP

Zaključci iz procene protivničkih snaga

- namere i mogućnosti protivničkih snaga

- moguće varijante dejstva i uticaj protivničkih

snaga na realizaciju osnovnih sadržaja LoP po

elementima i podsistemima

3. Procena zemljišta (teritorije)

- karakteristike orografskih, hidrografskih i

geoloških osobina i uticaj ovih osobina na angažovanje i LoP vlastitih snaga

- karakteristike osnovnih pravaca dejstva, prohodnost, komunikativnost, naseljenost

- značajne vazdušnodesantne prostorije

- pogodnost teritorije za zaštitu elemenata LoP od dejstva iz vazdušnog prostora, raseljavanje, disperziju i izmeštanje

Zaključci iz procene zemljišta

- osnovni pravci angažovanja snaga, putevi

- moguće korišćenje objekata i infrastrukture od

značaja za LoP

- uticaj većih naselja i reka na funkcionisanje LoP

2. Procena sopstvenih snaga

sastav, grupisanje, raspored i stanje jedinica,

ojačanja i drugih snaga u zoni

- operativno-taktički položaj

- raspored jedinica za logističku podršku

- mere koje treba preduzeti za uspešnu

realizaciju LoP u zoni dejstva

- najpovoljniji pravci za dotur i evakuaciju

- raspoloživost resursa jedinica i teritorije bitnih za realizaciju LoP

Zaključci iz procene sopstvenih snaga

- mogućnosti vlastitih snaga za LoP jedinica u fazi izvođenja $b / d$

- kako grupisati elemente LoP i šta treba posebno preduzeti, s obzirom na predstojeći zadatak i raspoloživost resursa jedinica $i$ teritorije

najcelishodnija organizacija LoP

- uticaj popunjenosti RMR na LoP jedinica

4. Procena vremena

- ukupno raspoloživo vreme do gotovosti - uticaj vremena na kvalitet realizacije LoP

- klimatski uslovi

Zaključci iz procene vremena

- uticaj raspoloživog vremena na izvršenje zadatka

- šta treba preduzeti da se vreme racionalno iskoristi i obezbedi dovoljno vremena za rad potčinjenih organa LoP

\section{Sl. 3 - Rad organa logističke podrške u pripremi i realizaciji odluke}


Redosled podnošenja predloga organa LoP

\begin{tabular}{|l|l|}
\hline & \multicolumn{1}{|c|}{ Redosled } \\
\hline 1. & NOLP \\
\hline 2. & NTP \\
\hline 3. & NInP \\
\hline 4. & NSnP \\
\hline 5. & NVtP \\
\hline 6. & NSbP \\
\hline 7. & NGrP \\
\hline 8. & NFnP \\
\hline
\end{tabular}

2. Predlog načelnika tehničke podrške 2.1. Snabdevanje TPS

- organizacija snabdevanja sredstvima energije boja (municija, gorivo,...) po etapama (periodima, fazama) - prioritet dotura po jedinicama i sredstvima - organizacija korišćenja izbora za snabdevanje preko državnih organa,

- način prikupljanja i korišćenja ratnog plena

2.2. Održavanje TPS

- organizacija održavanja i remont TPS formacijskim, pridodatim i kapacitetima teritorije

- prioriteti u remontu i mere za ubrzavanje remonta, organizaciji prikupljanja i izvlačenja oštećenih TPS

- postupak sa TPS koja se ne mogu blagovremeno popraviti

- organizacija i način snabdevanja i nabavke rezervnih delova

2.3. Ostali predlozi i zahtevi raspored izvršnih organa, način dotura i evakuacije, predlog za popunu nedostajućim sredstvima, raseljavanje i izmeštanje
1. Predlog načelnika odseka za OLP

1.1. Grupisanje i raspored logističkih jedinica i ustanova

- početno grupisanje, rejoni razmeštaja

- vreme gotovosti za rad

- naredni rejoni razmeštaja, način, vreme, pravci premeštanja

- organizacija oslanjanja na elemente LoP pretpostavljene komande, ustanove i preduzeća

1.2. Organizacija logističke podrške

- težište LoP

- prioritet po jedinicama i sredstvima etape (periodi, faze) $\mathrm{LoP}$

- organizacija i putevi dotura i evakuacije

- način LoP pridodatih jedinica u zoni dejstva

- pravci dotura i evakuacije

- saradnja sa organima vlasti i MUP

1.3. Ostale mere LoP

- sprovođenje osnovnih mera zaštite

- asanacija bojišta

- prikupljanje i preraspodela ratnog plena

- LoP ratnih zarobljenika

3. Predlog načelnika intendantske podrške

3.1. Organizacija snabdevanja InPS

- način dotura

- organizacija korišćenja vlastitih resursa, kapaciteta pretpostavljene komande i teritorije

3.2. Organizacija ishrane ljudi i životinja

- planiranje i organizacija ishrane

- obezbeđenje pekarskih i dr. proizvoda

- klanje stoke i obrada mesa

- organizacija ishrane životinja

- sanitarno-bezbednosne mere u ishrani

3.3. Obezbeđenje vodom i energentima

- planiranje, organizacija i realizacija obezbeđenja

vode, kupanje ljudstva, zagrevanje prostorija

3.4. Uslužne delatnosti

- radioničko održavanje InPS

- pranje rublja, hemijsko čišćenje

3.5. Ostali predlozi i zahtevi

raspored izvršnih organa, način dotura i evakuacije,

predlog za popunu nedostajućim sredstvima,

raseljavanje i izmeštanje

Sl. 4 - Podnošenje predloga načelnika službi pomoćniku komandanta za logistiku 
4. Predlog načelnika sanitetske podrške

4.1. Organizacija preventivno-medicinske zaštite - Organizacija mera opšte i lične higijene

- Sprovođenje kontrole ishrane i vode

- Sprovođenje mera za sprečavanje pojave straha i panike, širenja zaraznih i profesionalnih oboljenja

- Organizacija sanitetskog radiološko-hemijskog izviđanja i osmatranja

4.2. Zbrinjavanje povređenih i obolelih

- Organizacija rada i razmeštaj sanitetskih stanica i ustanova

- Način trijaže, evakuacije i lečenja povređenih i

obolelih

- Oslanjanje na kapacitete teritorije

4.3. Organizacija snabdevanja SnPS

4.4. Ostali predlozi i zahtevi

Raspored organa i korišćenje resursa teritorije, objedinjavanje i pretpočinjavanje kapaciteta, način evakuacije ranjenika iz dubine teritorije, predlog za popunu nedostajućim sredstvima, premeštanje, ...

6. predlog načelnika saobraćajne podrške

6.1. organizacija saobraćaja

- planski režim putnog saobraćaja

- kontrola i regulisanje saobraćaja

6.2. organizacija transporta

- putni transport

- železnički transport

- plovidbeni i vazdušni transport

6.3. mere bezbednosti i zaštite u saobraćaju i

transportu

6.4. ostali predlozi i zahtevi

Raspored organa i korišćenje resursa teritorije, objedinjavanje i pretpočinjavanje kapaciteta, predlog za popunu nedostajućim sredstvima, premeštanje, ...
5. Predlog načelnika veterinarske podrške

5.1. Organizacija sprovođenja veterinarsko-sanitarnog nadzora nad namirnicama životinjskog porekla

5.2. Zdravstvena zaštita životinja - Primena profilaktičkih,

protivepizootioloških i veterinarskih mera RHB zaštite

- Mere zbrinjavanja povređenih i obolelih životinja, trijaž, evakuacija, lečenje, izolacija

- Oslanjanje na kapacitete teritorije 5.3. Organizacija snabdevanja VtPS 5.4. Ostali predlozi i zahtevi

Raspored organa i korišćenje resursa teritorije, objedinjavanje i

pretpočinjavanje kapaciteta, popuna nedostajućim VtPS

7. predlog načelnika građevinske podrške

- upotreba izvršnih organa

- prostorno uređenje infrastrukture

- prilagođavanje prirodnih i veštačkih

objekata potrebama jedinica

- raščišćavanje ruševina

- upravljanje, opravka i održavanje

nepokretnosti

- saradnja sa organima teritorije

- primopredaja objekata
8. Predlog načelnika finansijske podrške

- organizacija finansijskog poslovanja

- način obezbeđenja jedinica gotovim novcem

- organizacija materijalnog knjigovodstva
- prenošenje odluke

- izviđanje

- izrada planova

- kontrola realizacije

Sl. 4a-Podnošenje predloga načelnika službi pomoćniku komandanta za logistiku 
Pri izradi planova još uvek se koriste zastarele metode i šablonizirani obrasci. Na primer, u uputstvu za vođenje radne karte nalazi se preko 700 simbola raznih dimenzija i preko 1000 skraćenica, a svaka promena situacije iznova se nanosi na kartu. Dinamika odvijanja borbenih dejstava na određenim pravcima uočava se tek kada se uporedi novonastala situacija sa prethodnom. Zbog sporog i ponekad nefunkcionalnog priliva informacija iz nižih nivoa ka višim, ucrtani podaci na karti bitno se razlikuju od situacije na terenu.

Istraživanja pokazuju da komande na višim nivoima uspevaju da obrade oko $30 \%$ prispelih informacija, dok u svom radu koriste manje od 30\% obrađenih informacija. Ovakva situacija prouzrokuje prikupljanje velikog broja informacija koje se ne koriste u sistemu, čime se bespotrebno iscrpljuju organi na nižim nivoima komandovanja. U pojedinim situacijama na višim nivoima komandovanja, izrađuje se veliki broj karata (jedna za komandanta i preko 20 karata raznih organa komande).

Otklanjanje uočenih nedostataka u klasičnom sistemu vođenja radne karte uspešno se rešava uvođenjem informacionog sistema za vođenje radne karte na računaru. Pod tim se podrazumeva prenos, obrada i prikaz veće količine informacija, čime se omogućava praćenje situacije $\mathrm{u}$ realnom vremenu, donošenje i distribucija pravovremenih i kvalitetnih odluka. To uslovljava klasifikaciju elemenata snaga, definisanje procedura i standardizaciju podataka u procesu vođenja radne karte. Ovako postavljeni informacioni sistemi razvijaju se po metodo- logiji razvoja geografskih informacionih sistema.

Geografski informacioni sistem (GIS) može se shvatiti kao racionalno organizovan skup hardvera, geografskih podataka i korisnika, koji je projektovan tako da omogućava efikasno prikupljanje, čuvanje, ažuriranje, analizu i prostorno prikazivanje geografskih i svih drugih informacija koje su od interesa za korisnika [4].

Ovako organizovan sistem čine dve grupe podataka - sa učestalom promenom i sa sporom promenom. Učestalu promenu podataka vrše korisnici sistema u jedinicama. Oni ažuriraju podatke u vezi s elementima snaga i njihovo grafičko predstavljanje u prostoru. Sporo promenljive podatke, koji se koriste za analizu i prikaz prostornih veličina, ažuriraju pojedini profesionalni sastavi vojske (VGI...).

Vođenje elektronske karte ima višestruku korist za organe logistike, posebno zbog mogućnosti povezivanja podataka sa karte i pripremljenih baza podataka koje treba da budu ažurne i čiji se podaci neposredno koriste pri donošenju odluke. Organi logističke podrške imaju izraženu potrebu da u miru regulišu lokacije za raseljavanje i disperziju ratnih materijalnih rezervi i izmeštanje remontnih, proizvodnih i uslužnih kapaciteta. Formiranjem baza podataka i njihovim uvezivanjem u informacioni sistem na mnogo lakši način bi se blagovremeno donosile adekvatne odluke. Po potrebi, i u zavisnosti od raspoloživog vremena, korišćenjem podataka iz ovih baza mogla bi da se vrši i višekriterijumska optimizacija ili ekspertska analiza. 


\section{Zaključak}

Rad komande zahteva visoku stručnost, dobru organizaciju i izbor pravilnog metoda rada u nametnutoj situaciji. Prikupljanje i efikasna obrada podataka u velikoj meri utiču na kvalitet odluke. U vreme kada se teži upravljanju svih procesa, neophodno je preduprediti događaje pravilnim procenama, a najteža varijanta je da se otklanjaju posledice. Zbog toga informacionim tokovima treba dati prioritetan značaj, jer bez upotrebljivih informacionih tokova upravljačka funkcija u sistemu logističke podrške može iskazati slabosti. Uvid u stanje sistema je osnovni preduslov za pravilnu postavku organizacije, preduzimanje mera za poboljšanje elemenata sistema, pravilno grupisanje snaga i sredstava i racionalno korišćenje resursa.

Prikupljanje podataka treba da se vrši za jedan logistički lanac, a ne za više lanaca ili sistema. Jedan podatak prikuplja se na jednom definisanom mestu, a koristi se u celom lancu ili sistemu.
Za efikasnu logističku podršku i stalno upravljanje njenim procesima neophodno je definisati, standardizovati i koristiti baze podataka $\mathrm{u}$ jedinstvenom informacionom sistemu. Na taj način rad komande, donošenje odluka i upotreba snaga biće optimalni.

Literatura:

[1] Andrejić, M. i dr.: Definisanje kriterijuma za izbor rejona razmeštaja tehničkih jedinica za održavanje, VTG 1/1996, (str. 14-18).

[2] Grupa autora: Iskustva iz rada bataljona remontne podrške, 1999.

[3] Uputstvo za raseljavanje, disperziju i zaštitu pokretnih stvari (privremeno) - nacrt, GŠ, SL, OUL, 2003.

[4] Vojne softverske aplikacije nad digitalnom kartom, radni mat., 2004 (str. 9-16).

[5] Cakić, A.: Logistički kontroling u savremenim logističkim sistemima, VTG 1/2003 (str. 49-50).

[6] Nikolić, M. i dr.: Kvantifikacija osnovnih kriterijuma logistike, VGT 1/2004 (str. 27-29)

[7] Jovanović, D.: Mogućnost poboljšanja tehničkog održavanja u realnom sistemu, 1998 .

[8] Stanojević, P. i dr.: Strategije održavanja tehničkih sistema, VTG 6/2003 (str. 543-545).

[9] Grupa autora: Iskustva iz rada bataljona remontne podrške u toku rata 1999. godine, 1999 (str. 4-11).

[10] Uputstvo za rad komandi - štabova (nacrt), GŠ, 1983 (str. 46-74).

[11] Prilozi uz uputstvo za rad komandi - štabova (nacrt), 1983 (str. 7-16).

[12] Stojiljković, M.: Organizacija rada kao naučna disciplina (lekcije), CVVTŠ-TŠC 1973.

[13] Borović, S.: Organizacija rada (lekcije), CVVTŠ-TŠC 1973.

[14] Miladinović, V.: Sistemski prilaz optimalnom planiranju armijskog transporta (doktorski rad), TVA KoV JNA, 1980.

[15] Mišić, R. Ž.: Strategija, VINC, 1993 (str. 646-658). 